- be of much more interest to historians, she says, because it contains an early sketch of DNA. That, she adds, "would be much better placed in an archive".

In the early 2000s, Crick nearly sold his papers to a private buyer. Watson urged him to reconsider the sale, and in 2001, the Wellcome Trust, a London-based biomedical charity, purchased the papers for $£ 1.6$ million (US\$2.4 million). The Wellcome Library recently launched a website containing digitized versions of the collection.

Simon Chaplin, director of the Wellcome Library, says that the Crick memorabilia now at auction are a "low priority" for Wellcome. "I think it would be nice if the medal could be available to the public, but I feel it's more important to present the substance of somebody's research than to focus on individual items that may be intrinsically valuable," he says. He suggests that the medal and other items would be better suited to London's Science Museum: its collection includes a reconstruction of Watson and Crick's first model of the DNA double helix, complete with some pieces from the original model, which was destroyed.

Robert Bud, the museum's principal curator of medicine, says "it's our business whether

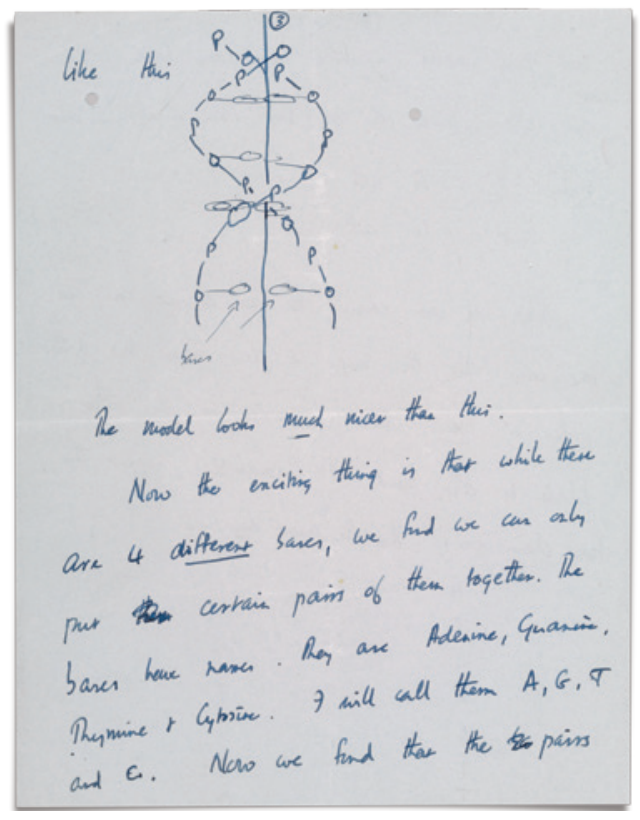

"A most important discovery," wrote Crick to his son.

we're going to bid for it", but that "if somebody were to give it to the Science Museum I would doubt we would reject it". Museums, adds Bud, can make scientific memorabilia more worthwhile by presenting objects within a larger story. "It makes the past real, and enables you to believe that the future with which you're working has a real ancestry," he says.

It is uncommon - although not unheard of - for scientific collectables to wind up at auction, adds Bud. In 1997, his museum bought a preserved penicillin mould, prepared by Alexander Fleming, for around $\$ 25,000$ from Christie's. And in November 2012, a Danish auction house garnered 280,000 Danish kroner (US\$48,000) for the Nobel medal that Aage Niels Bohr won in 1975 for his theoretical work on the structure of the atomic nucleus. His father Niels Bohr, a pioneer of the field of quantum physics, and August Krogh, the 1920 medicine laureate, auctioned their medals in 1940 to raise money for a fund to aid the Finnish people during the Second World War. An anonymous buyer has since given the medals to the Danish Historical Museum in Fredriksborg.

Neuroscientist Charles Stevens, a former colleague of Crick's at the Salk Institute, isn't bothered by the family's decision to auction the medal. "The things that I would treasure from him are things he actually did," he says. Nor does he think that Crick would mind. "Francis didn't make the medal - he just won it. I'm sure he was glad he got it, but I doubt he would be very sentimental." -

\title{
Sizing up a slow assault on cancer
}

\section{Rise of immunotherapies spurs search for markers of response.}

\section{BY HEIDI LEDFORD}

$\mathrm{J}$ edd Wolchok braced himself as he walked into the examination room to deliver bad news to his patient. Scans showed that the man's advanced melanoma had spread, and new tumours had sprouted, even though he had received an experimental therapy called ipilimumab (Yervoy) to rally his immune system against the disease. "In my mind I was rehearsing the standard speech," says Wolchok, an oncologist at the Memorial Sloan-Kettering Cancer Center in New York. "I'm sorry Mr Soand-so, but the treatment doesn't seem to be working." Instead, the patient stopped Wolchok at the door. "Now before you show me your pictures, let me tell you: I feel better," he said.

Wolchok took a gamble, and continued the therapy. More than six years later, his patient is thriving, and the drug, made by Bristol-Myers
Squibb of New York, has been approved by the US Food and Drug Administration. In that time, other experimental immunotherapies have shown promise, and clinicians have become increasingly familiar with delayed responses such as the one Wolchok's patient experienced - which reflect a gradual attack by the immune system, in contrast to the rapid onslaught of toxic chemotherapies. They still have no tools to quickly discern which patients are benefiting from treatment, but that may be about to change.

At the annual meeting of the American Association for Cancer Research in Washington DC this week, Wolchok and other researchers will report on their search for immunotherapy markers - ways to predict a patient's response to an immunotherapy or to show whether a given treatment is working. The work is hampered by the complexity of the immune system,

but early results are converging on one point: that patients' own immune responses to cancer are crucial in determining outcomes.

"When you sum it all up in many different cancers, early and late stage, it looks like patients who have a 'smouldering' initial immune response to cancer are more likely to benefit from immune therapies," says Thomas Gajewski, a cancer researcher at the University of Chicago in Illinois. Early work suggests that such patients may fare better, irrespective of the therapy used to treat them, he says. The evidence is fuelling a push to add an immune component to standard tumour pathology evaluations (see 'T cells can brighten

"It looks like patients who have a 'smouldering' initial response to cancer are more likely to benefit." prognosis').

Reliably gauging the initial response, however, is a challenge, cautions Mario Sznol, an oncologist at Yale University in New Haven, Connecticut. The immune response is a moving target, influenced not only by a patient's genetic make-up and environment, but also by proteins secreted by the tumour that can suppress immune cells. Immune markers present in the blood may not reflect what is happening in the tumour, and variation within a tumour means that biopsies may not paint a full picture either, if the needle misses 


\section{CANCER STAGES \\ T cells can brighten prognosis}

For more than half a century, pathologists have assessed the severity of a cancer using the same basic framework: tumour size, the cancer's presence in lymph nodes and whether it has spread to other parts of the body. Called 'TNM staging', the framework ranges from stage 1 , which has a relatively good prognosis, to stage 4 , which can require immediate and aggressive therapy.

But researchers are now wondering whether it is time to add an 'i' category to the test - by factoring in whether immune cells are present in or around the tumour. In 2006, Jérôme Galon of the National Institute of Health and Medical Research in Paris and his colleagues found that the presence of $T$ cells in or around colon cancers was associated with better patient outcomes ${ }^{2}$. They then applied the screen to samples from 599 patients and found that the immune response predicted outcomes more accurately than the TNM staging system ${ }^{3}$.

The results have spawned an effort to test the 'immunoscore' approach at 23 sites in 17 countries. Researchers will mine stored specimens and associated hospital records for 6,000 colon-cancer patients. Results are expected in the autumn. Bernard Fox, who studies immunotherapies at Oregon Health \& Science University in Portland, hopes that the test will also work for other cancers in which T cells can infiltrate tumours, such as breast and ovarian cancer. But he worries that biopsies for these other cancers are often not as large - in colon cancer, the entire tumour plus surrounding tissue is typically taken.

Yet if the colon-cancer results hold up at scale, it could prompt a radical change in thinking, he says. "In the current staging system, pathologists consider immune cells a contaminant," says Fox. "Isn't it incredible that they may be the key to survival?" H.L. any patches of immune cells that have infiltrated the tumour.

Some are hoping that new methods will fill the gap. Adaptive Biotechnologies, based in Seattle, Washington, uses intensive DNA sequencing of blood and tissue samples to profile the changes in specialized receptors found in populations of immune cells called T cells. These cells make the receptors by shuffling variable regions of DNA in response to antigen exposure. Chief executive Chad Robins says that the company hopes the assay will be sensitive enough that blood samples alone could be used to monitor patients' responses to immunotherapy. Demand for the technique has skyrocketed in the past year, he says, as more and more companies seek to test its potential to guide immunotherapy decisions.

Suzanne Topalian, an oncologist at Johns Hopkins University in Baltimore, Maryland, focuses instead on the cancer cells. A number of the world's biggest pharmaceutical companies are developing therapies that release a brake on the immune system by inhibiting a protein called programmed death 1 (PD-1) or its partner, programmed death ligand 1 (PD-L1). A study by Topalian and her colleagues ${ }^{1}$ suggests that these therapies work best if at least $5 \%$ of a patient's biopsied tumour cells express PD-L1. Some companies have already made PD-L1 expression a requirement for participation in their clinical trials - a move that both Topalian and Wolchok worry is premature. "I certainly would not want to exclude a patient from a trial for a PD-1-pathway blocking drug," says Wolchok. "Even if one tumour biopsy is negative, the patient may have other tumours that are positive."

While Topalian and others hunt for useful immunotherapy markers, academic labs are trying to understand what ignites the smouldering immune response to cancer in the first place. "Why do some patients have this response when others don't?" asks Sznol. "Understanding this could lead us to new therapies."

1. Topalian, S. L. et al. N. Engl. J. Med. 366, 2443-2454 (2012).

2. Galon, J. et al. Science 313, 1960-1964 (2006).

3. Mlecnik, B. et al. J. Clin. Oncol. 29, 610-618 (2011).

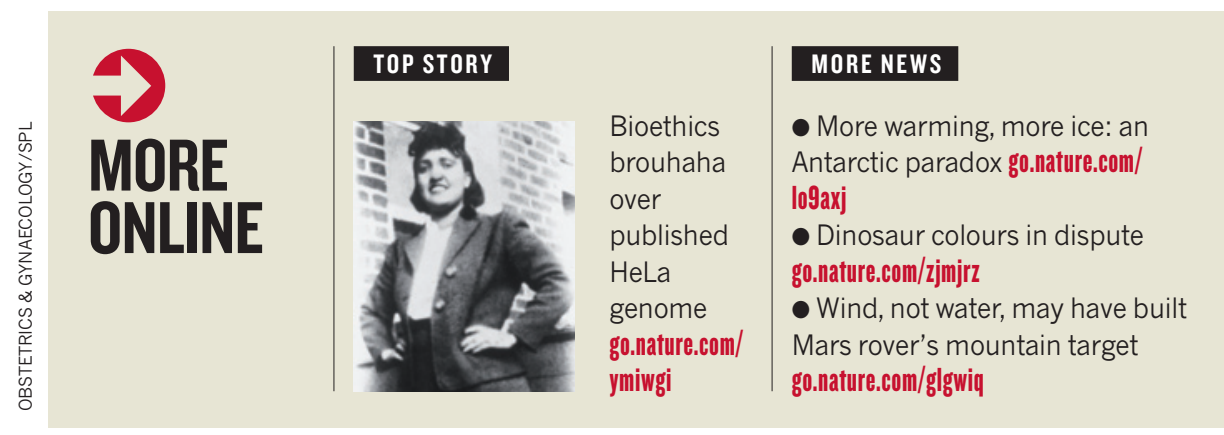

